\title{
PATENTWATCH
}

\section{'Optional' ingredients anticipate}

A case between generics manufacturer Upsher-Smith Laboratories and pharmaceutical company PamLab LLC has further highlighted the importance of language in claim construction, this time in the context of pharmaceutical formulation. Upsher-Smith holds two patents issued in 1999 and 2003 that relate to vitamin supplement compositions containing one or more of vitamins $\mathrm{B}_{12}, \mathrm{~B}_{6}$ and folic acid. The two companies were arguing over whether these patents were anticipated by a European Patent Application (EPA) filed by Pamlab in 1993 that discloses the same vitamin compositions as the two Upsher-Smith patents but with the optional inclusion of antioxidants.

Victor Herbert, the named inventor on the Upsher-Smith patents, distinguished the two patents from prior art on the basis of the discovery that it was the antioxidant property of certain excipients in the described compositions that destroys some of the vitamin components, and therefore his patents claim compositions that expressly exclude antioxidants. The issue at hand in this case was whether the EPA filed by PamLab, which 'optionally' includes antioxidants, anticipates UpsherSmith's claims, which 'expressly' excludes antioxidants from the compositions.

Because the compositions claimed in the EPA optionally include antioxidants, the US Appeals Court ruled that the EPA essentially teaches two different compositions - one including and one excluding antioxidants - therefore, the composition excluding antioxidants anticipates the Upsher-Smith compositions. Upsher-Smith's argument that the EPA describes a 'genus' of vitamin compositions that cannot anticipate the 'species' of compositions claimed in its patents was also dismissed by the Appeals Court on the basis that the compositions specified in both the EPA and the two patents were equally broad. Despite the fact that Herbert was the first to discover how certain antioxidants destroyed vitamin $B_{12}$ and folate - an observation that had been noted previously but not explained - the Appeals court ruled that this did not entitle him to "remove that prior art from the public domain" by patenting those compositions. The Appeals Court therefore affirmed the decision of the District Court that the Upsher-Smith patents are anticipated and invalid.

Joanna Owens

http://www fedcirgov/opinions/04-1405 pof 